\title{
Drought in the U.S. Caribbean: Impacts on Crops
}

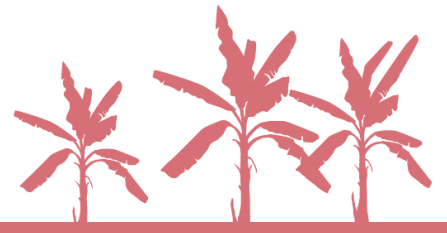

Authors: Eva Holupchinski, Nora Álvarez-Berríos, William Gould, and Josh Fain (USDA Caribbean Climate Hub, USFS)

Graphic: Integration \& Application Network, University of Maryland Center for Environmental Science

Agricultural production in Puerto Rico and the U.S. Virgin Islands (USVI) is important for the region's economy, food security, and rural livelihoods. Farms in the region are mostly small-scale and cultivate a wide variety of crops including plantains, vegetables, coffee, hay, and ornamental plants. Small-scale farms of 10 acres or less are much more common in the U.S. Caribbean than in the continental U.S. While the variety of crops these farms provide is vital to the region, smaller financial margins can make them more vulnerable to climate-related hazards.

Of the many climate events that threaten agricultural production in the region, increasing drought is one of the most devastating. agricultural sector is typically the first to feel the impacts of drought, since the majority of crops in the U.S. Caribbean are rain-fed. Drought conditions can quickly lead to reduced crop yield, desiccation and crop losses island-wide. The As the climate changes, droughts in the U.S. Caribbean are projected to become more frequent and intense. Implementing the use of cover crops, water retention ponds, and drought tolerant varieties can help reduce the impacts of drought.

\section{About this Series}

This fact sheet is part of a series examining what we know about the impacts of drought on ecosystems and agriculture in the U.S.

Caribbean. Explore the other fact sheets on:

- Coastal Estuary Ecosystems

- Freshwater Ecosystems

- Tropical Forest Ecosystems

- Livestock

View the complete series here: usgs.gov/casc//slandDrought

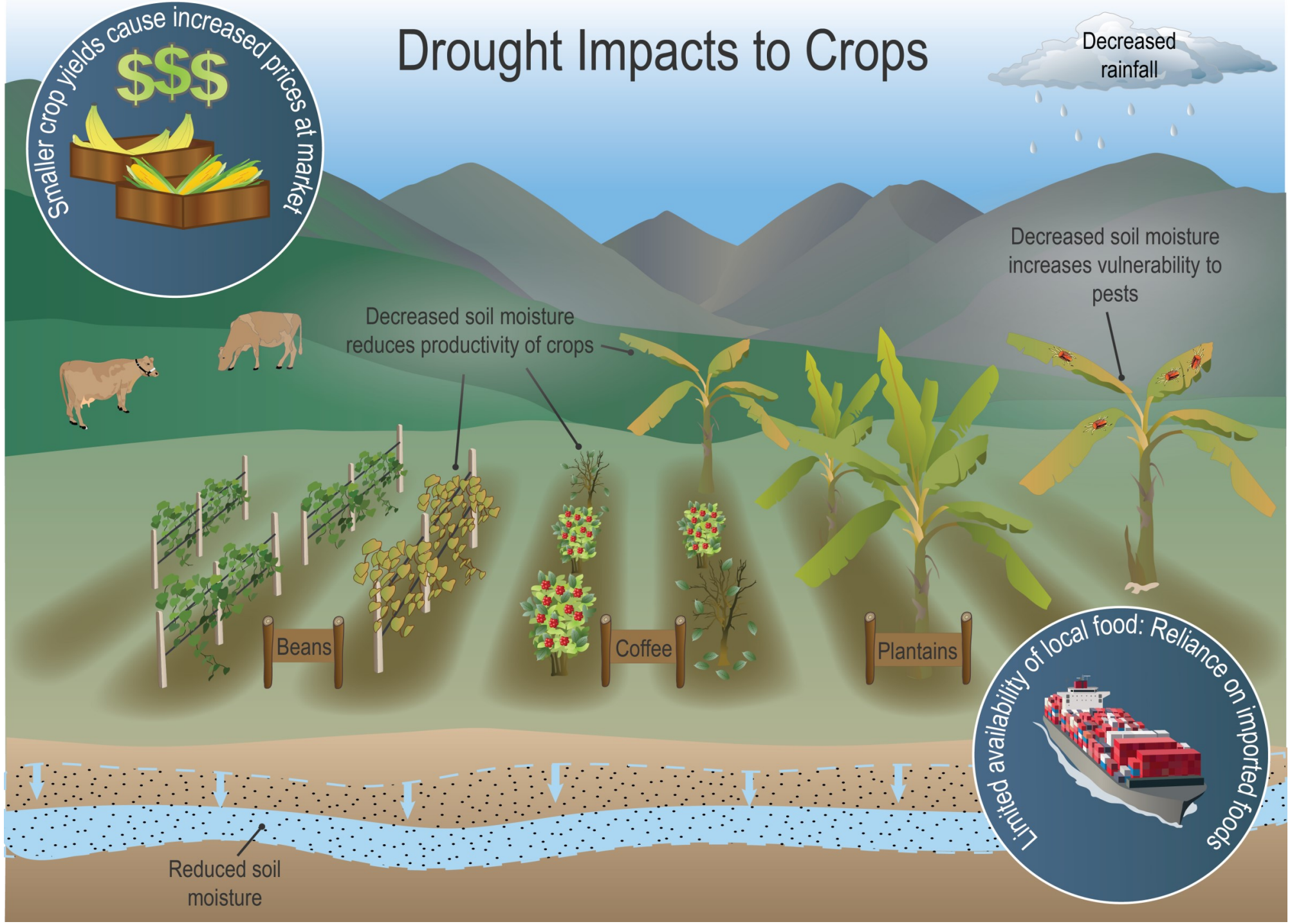




\section{Short-Term Impacts}

\section{Long-Term Impacts}

Produce Quality: Drought can stunt growth, resulting in smaller, lower quality produce.

- Higher Prices: Lower yields and higher operating costs can mean higher prices for consumers.

Vulnerability to Pests: As soil moisture decreases, crops dry out and become more vulnerable to insects.
- Local Food Availability: As staple crops are impacted, there will be a reduction in the availability of local food. Imported food is often less fresh, with lower nutritional value.

Saltwater Intrusion: Overuse of groundwater for irrigation could lead to more salt-water intrusion into aquifers.

- Coffee Production: Coffee production may be reduced due to less optimal conditions and an increase in pests.

\section{Spatial Impacts}

Since 2000, all regions of Puerto Rico have been exposed to some level of drought conditions. The east and southeastern regions have experienced the most frequent droughts. In 2014, the coffee-growing industry was among the most impacted by drought. In the drought of 2015 , the most heavily impacted crops in Puerto Rico were grass, fodder, and plantains, accounting for $85 \%$ of the $\$ 14$ million in agricultural losses caused by drought. In the USVI, the impacts of the 2015 drought were most notable in the eastern regions of St. John and St. Thomas and across the entire island of St. Croix.

\section{Gross-Sector Impacts}

Economic: Drought conditions lead to increased expenses for farmers which results in elevated prices for local food and an increased reliance on imported food products.

Water Supply: Reduced freshwater availability can lead to conflicts between agricultural and other sectors.

\section{Gurrent Activities \& Future Research Directions}

The USDA Natural Resource Conservation Service (NRCS) - Caribbean Area is helping U.S. Caribbean producers in mitigating the effects of drought. Recommended practices include establishing cover crops for improved water infiltration, installing efficient irrigation systems for effective water resource use.

The Scientific Drought Committee of Puerto Rico works to advise the local government on recommended strategies for water conservation as drought conditions progress.

Further research on drought-tolerant crops will help local producers adapt to more frequent drought events and decreased rainfall. This research is underway, and two varieties of drought-tolerant common beans were recently developed at the USDA Agricultural Research Service Tropical Agricultural Research Center in Mayagüez, Puerto Rico.

\section{About Us}

This fact sheet is a product of the 2018 U.S. Caribbean Drought Workshop, hosted by the USDA Caribbean Climate Hub in collaboration with the Climate Adaptation Science Center (CASC) network. View a more detailed description of drought impacts on crops at usgs.gov/casc//slandDrought

CASCs: Delivering science to help fish, wildlife, water, land, and people adapt to a changing climate. Learn more: usgs.gov/casc Caribbean Climate Hub: Developing and delivering climate adaptation information. Find resources and tools at caribbeanclimatehub.org and climatehubs.oce.usda.gov/hubs/caribbean. International Institute of Tropical Forestry, Río Piedras, Puerto Rico. The USDA is an equal opportunity provider, employer and lender. 